\title{
THE CONTRIBUTION OF GASTRIC EMPTYING SCINTIGRAPHY TO THE TREATMENT OF OBESITY WITH GASTRIC BANDAGE - PRELIMINARY RESULTS
}

\author{
Pavel Hladik ${ }^{\text {a*, }}$ Jaroslav Vizda ${ }^{\mathrm{b}}$, Eva Malac ${ }^{\mathrm{c}}$ Zdenek Zadak ${ }^{\mathrm{d}}$, Tomas Hroch ${ }^{\mathrm{a}}$ \\ a Department of Surgery, Faculty Hospital and Faculty of Medicine, Hradec Kralove, Czech Republic \\ ${ }^{b}$ Department of Nuclear Medicine, Faculty Hospital and Faculty of Medicine, Hradec Kralove \\ c Department of Metabolic Care and Gerontology. Faculty Hospital and Faculty of Medicine, Hradec Kralove \\ ${ }^{d}$ Centre for Science and Research. Faculty Hospital and Faculty of Medicine, Hradec Kralove \\ e-mail: hladik.pav@gmail.com
}

Received: November 15, 2007; Accepted (with revisions): March 22, 2008

Key words: Morbid obesity/Bariatric surgery/Gastric banding/Gastric emptying scintigraphy

Introduction: Gastric banding for morbid obesity is among the least mutilating of procedures used in bariatric surgery and is classified as a restrictive surgical method. Although it is widespread, so far, however the mechanism responsible has not been fully explained.

Methods and results: The authors present the preliminary results from scintigraphic examination of the evacuation ability of the stomach using food labeled with ${ }^{99 \mathrm{~m}} \mathrm{Tc}$-colloid in six obese patients with a gastric bandage. This initial study showed that the functionality of the bandage demonstrated as a significant drop in body weight, is connected with slower evacuation of the stomach. However, the use of adjustable bandages would have significantly slowed and restricted the passage of food through the cardia of the stomach.

Conclusions: Since it can be extremely difficult to adequately objectively determine the functionality of gastric bandages, evaluating the gastric emptying scintigraphy may be useful in fulfilling this purpose.

\section{INTRODUCTION}

Surgical methods used in the treatment of obesity are on the rise around the world. The first operative procedure for treating morbid obesity was a jejunoileal bypass performed in 1954.

The surgery is based on two principles, firstly there are restrictive surgical procedures after which there is a reduction in food intake and second, another group of procedures that causes malnutrition. In certain cases both procedures can be combined ${ }^{1,2}$.

Most commonly there are three types of operations performed - adjustable gastric bandage (AGB), gastric bypass and duodenal switch. AGB is the simplest operative procedure. It can enforce a drop in body weight of around $15-20 \%$. Mortality is less than $0.2 \%$. A more drastic reduction in body weight can be achieved by a gastric bypass with a "Roux-en-Y" diversion. Operative mortality is less than $0.2 \%$, for a laparoscopic operation and under $0.5 \%$ for the open surgery. Duodenal switch is an operation which is followed by the greatest weight reduction. However malabsorption may occur requiring mineral and vitamin supplementation ${ }^{3}$.

Some surgical procedures are easily reversible. Others are severely mutilating with limited possibility of restitution. It is important to understand that obesity involves more complication risks more than normal weight patients. Further, it is unfortunately true that surgery for morbid obesity does not guarantee a definite reduction in body weight in all patients ${ }^{4}$.

\section{PATIENTS AND METHODS}

Scintigraphic examination of the evacuation ability of the stomach (gastric emptying scintigraphy) was done on 6 patients whose obesity was surgically treated by adjustable gastric bandage. The examination was performed before and after the operative procedure. In the post operative group, it was performed prior to adjusting the bandage. The preoperative and postoperative body weights were compared along with the stomach emptying half-times prior to and after the procedure.

This study is only a small pilot group of 6 patients. The average age was 42.3 years (31-46). The average value of BMI (body mass index) in the group was 45.5 (40-54.6).

The gastric bandage was applied using a laparoscopic method. Adjustable bands Soft Gastric Band Premium Standard, A.M.I. GmbH, Feldkirch, Austria were used.

The gastric emptying scintigraphy was performed after giving standard meal - one scrambled egg (60-70 g) labeled with ${ }^{99 \mathrm{~m}} \mathrm{Tc}-$ colloid (activity of 40-50 MBq), placed between two slices of white bread (about $50 \mathrm{~g}$ of bread) lightly buttered (about $5 \mathrm{~g}$ of fat) and $150 \mathrm{ml}$ of water (to assist in swallowing the solid meal). The acquisition of data was done by dual-headed gamma camera Varicam Elscint in the supine position of patient from anterior and posterior projections over a period of 90 to 120 minutes. For the data processing, a standard protocol to determine the emptying half-times from the raw data and from exponential fitting curves was used. Date points were corrected 
for radionucline decay. Mathematical correction for attenuation was then done by calculating the geometric mean of the counts in the anterior and posterior views at each date point. During the study the so called lag phase was also taken into account during which the labeled food remained in the stomach prior to the start of emptying.

The patients completed questionnaires on life quality. All patients involved in the study signed an informed consent. The project was approved by the ethics committee of the University Hospital in Hradec Kralove.

\section{PRELIMINARY RESULTS}

Prior to the operation all patients had either normal or slightly faster evacuation of stomach contents from the scintigraphic examination. Normal stomach emptying half-time is considered to be in the range of 25-45 minutes.

The results of the examinations are presented in table 1 . The time intervals of the stomach emptying halftimes are shown in minutes and both values in all cases - using exponential curve fitting / calculated from raw values. In this manner the times are presented in the text as well as in table 1 .

The preoperative average half-time was 24.2/31.7 minutes in the group of 6 examined patients. Following the operation four patients had slower emptying half-times, on average 52.7 / 63.2 minutes. In these cases, a remarkable reduction in body weight was observed: an average of $15.8 \mathrm{~kg}\left(\mathrm{BMI} 5.83 \mathrm{~kg} / \mathrm{m}^{2}\right)$. The table presents these patients under numbers 1 to 4 . In two patients (the remaining two patients in Table 1), the scintigraphic examination did not reveal a significant prolongation of emptying halftime. In these patients no significant reduction in body weight was found prior to band adjustment (table 1).

\section{DISCUSSION}

Peri and postoperative complications are common in surgical procedures during which the integrity of the digestive tract is disturbed. In comparison to conservative treatment for obesity, it is actually the most serious disadvantage of the surgical treatment.

After each operative procedure there is the possibility of complications in the form of interference with wound healing - operating wound infection or infection around foreign bodies which can be, for example, the adjusting devices for gastric bandage. Clearly disastrous results can be caused by perforation of the gastric cardia at the site of the gastric bandage application. The probability of severe complications is higher especially in resection procedures at the site of anastomosis of hollow organs ${ }^{5,6}$ (leakage of anastomosis, possibility of peptic ulcer developing in gastro-entero anastomoses). There is the possibility of mucosal atrophy and later the formation of metaplasia or even dysplasia in cases of long term chemical irritation ${ }^{7}$. Carcinoma in a bypassed stomach is not commonly reported in the literature. Nevertheless in case it is found, it is necessary to perform a retrograde entero-gastroscopy ${ }^{8}$ and surgical treatment is very difficult in these cases $^{9-11}$.

In patients with existing gastro-esophageal reflux disease it is wise to use more care when applying the gastric bandage. The condition, due to stagnation of food, in front of the bandage, can aggravate the more severe form

Table 1: The relation between weight loss and significant slowing of stomach evacuation.

Gastric emptying half-time is shown in minutes, in two values: with exponential fitting / according to raw values.

\begin{tabular}{|l|c|c|c|c|c|c|c|c|}
\hline & Initials & $\begin{array}{c}\text { Age } \\
\text { (years) }\end{array}$ & $\begin{array}{c}\text { BMI } \\
\text { before } \\
\text { operation }\end{array}$ & $\begin{array}{c}\text { BMI } \\
\text { after } \\
\text { operation }\end{array}$ & $\begin{array}{c}\mathrm{T} 1 / 2 \\
\text { before } \\
\text { operation }\end{array}$ & $\begin{array}{c}\mathrm{T} 1 / 2 \\
\text { after } \\
\text { operation }\end{array}$ & $\begin{array}{c}\text { BMI } \\
\text { difference }\end{array}$ & $\begin{array}{c}\mathrm{T} 1 / 2 \\
\text { difference }\end{array}$ \\
\hline 1. & $\mathrm{KH}$ & 31 & 41.4 & 35.1 & $30.0 / 47.0$ & $88.5 / 97.0$ & 6.3 & $58.5 / 50$ \\
\hline 2. & MI & 40 & 43.4 & 37.1 & $17.0 / 32.0$ & $24.2 / 51.6$ & 6.3 & $7.2 / 19.6$ \\
\hline 3. & MM & 44 & 54.6 & 48.3 & $21.9 / 30.8$ & $48.0 / 48.0$ & 6.3 & $26.1 / 17.2$ \\
\hline 4. & ZP & 38 & 42.0 & 37.6 & $26.8 / 14.5$ & $50.0 / 56.0$ & 4.4 & $23.2 / 41.5$ \\
\hline 5. & HA & 46 & 52.0 & 49.5 & $25.0 / 36.0$ & $33.0 / 44.8$ & 2.5 & $8.0 / 8.8$ \\
\hline 6. & MJ & 55 & 41.8 & 40.2 & $25.0 / 30.0$ & $27.2 / 39.0$ & 1.6 & $2.2 / 9.0$ \\
\hline
\end{tabular}

BMI - Body mass index

T $1 / 2$ - Gastric emptying half-time. 
of reflux eosphagitis. In cases of dysphagia it should be followed up with endoscopic examination of the esophagus to exclude the possibility of hidden symptoms arising from esophageal carcinoma ${ }^{12}$.

The ideal operative procedure for obesity would be an operation which is minimally burdened by peri and postoperative complications, least mutilating for the patients' gastrointestinal tract, is reversible if possible and produces a significant reduction in patient body weight. In practice a compromise between two main requirements needs to be met - an induced reduction in body weight and lower risk of operative complications. The surgical procedures could be tailored for individual patient ${ }^{13}$.

A very compromising opinion is that of Balthasar et al. who recommends a laparoscopic sleeve gastrectomy (LSG) in patients with a BMI over 55. In less obese patients an adjustable gastric bandage can be attempted with subsequent conversion into LSG if unsuccessful ${ }^{14}$.

In European countries, the most common bariatric procedure is considered to be the AGB.

The main complications of this method are slippage, infection, intragastric migration (erosion) and esophageal dilatation ${ }^{15,16}$. These complications can be corrected by implantation of a new band or conversion to another bariatric procedure.

The mechanism responsible in the case of $A G B$ is not yet clearly explained. The standard main criterion for evaluating the effect of gastric bandage is bodyweight monitoring. However, this is the secondary consequence of the gastric bandage, placed into the gastric cardia region, which is a region that is particularly important for the regulation of dietary intake ${ }^{17,18}$.

Winkler ${ }^{19}$ emphasizes the necessity for finding an objective and reproducible method that can exactly determine the functionality of gastric bandage bands.

In an experimental study the botox-A application to the gastric antrum in obese rats leads to weight loss by increasing the gastric emptying time ${ }^{20}$. In A. Cardoso et al. ${ }^{21}$ morbidly obese and non-obese subjects were examined by ${ }^{13} \mathrm{C}$-octanoic acid breath test and ${ }^{13} \mathrm{C}$-acetic acid breath test for gastric emptying half-time. The results demonstrated a significantly shorter gastric emptying half-time in obese patients compared to lean subjects. In obese subjects the caloric intake increases due to more rapid loss of satiety. In our study the successful weight loss after gastric banding procedure was demonstrated in patients with longer gastric emptying half-time.

According to our preliminary results, the scintigraphic examination of gastric evacuation has the potential for control of functionality of gastric bandage bands. During the actual examination, there is no risk of side effects and the radiation exposure is completely acceptable. The effective radiation dose ranges around $1 \mathrm{mSv}^{22}$, the procedure is tolerated by patients without any difficulties.

Longer follow-up and larger numbers of patients are needed to clarify the influence of gastric bandage bands to changes in gastric emptying half-time.

\section{CONCLUSION}

Our preliminary results showed longer half-time of stomach evacuation in obese patients who had a rapid drop in weight even prior to adjusting the gastric bandage.

The scintigraphic method aided the evaluation of gastric emptying ability and can be used to confirm the effectiveness of the gastric bandage bands.

\section{ACKNOWLEDGEMENT}

The study was supported by the research project $M Z O$ 00179906

\section{REFERENCES}

1. Livingston EH. Obesity and its surgical managment. Am J Surg 2002; 184:103-13.

2. Weber, M., Clavien, PA. Bariatric surgery - a successful way to battle the weight crisis. Br J Surg, 2006, Vol. 93, s. 259-260.

3. Wilding JPH. Treatment strategies for obesity. Obesity Reviews, 2007; 8:137-44.

4. Mervyn D. Surgery for the morbidly obese patient. FDCommunications Inc. Victoria Terrace P.O., North York, Canada. ISBN 0-9684426-0-9. 1989.

5. Luján JA, Frutos MD, Hernádez Q, Cuenca JR, Valero G, Parrilla P. Experience with the circular stapler for the gastrojejunostomy in laparoscopic gastric bypass (350 cases). Obes Surg 2005; 15:1096102.

6. Baker RS, Foote J, Kemmeter P, Brady R, Vroegop T, Serveld M. The science of stapling and leaks. Obes Surg 2004; 14:1290-8.

7. Sapala JA, Wood MH, Flake Jr TM. Marginal ulcer after gastric bypass: A prospective 3-year study of 173 patients. Obesity Surgery 1998; 8:505-16.

8. Lord RV, Edwards PD, Coleman MJ. Gastric cancer in the bypassed segment after operation for morbid obesity. Aust NZ J Surg 1997; 67:580-2.

9. Papakonstantinou A, Moustafellos P, Terzis I, Stratopoulos C, Hadjiyannakis E. Gastric cancer occuring after vertical banded gastroplasty. Obesity Surgery 2002; 12: 118-20.

10. Zirak C, Lemaitre J, Lebrun E, Journé S, Carlier P. Adenocarcinoma of the pouch after silastic ring vertical gastroplasty. Obes Surg 2002; 12:693-4.

11. Trincado TM, del Olmo JCM, Castano JG, Cuesta C, Blanco JI, Awad S, Carbajo MA. Gastric pouch carcinoma after gastric bypass for morbid obesity. Obes Surg 2005; 15:1215-1217.

12. Snook KL, Ritchie JD. Carcinoma of esophagus after adjustable gastric banding. Obes Surg 2003; 13:800-802.

13. Riele WW, Vogten JM, Boerma D, Wiezer MJ, Ramshorst B. Comparison of weight loss and morbidity after gastric bypass and gastric banding. A single center European experience. Obes Surg 2008; 18:11-16.

14. Balthasar A, Serra C, Pérez N, Bou R, Bengochea M, Ferri L. Laparoscopic Sleeve gastrectomy: A multipurpose bariatric operation. Obes Surg 2005; 15:1124-8.

15. Suter M, Giusti V, Heraief E, Calmes JM. Band erosion after laparoscopic gastric banding: Occurrence and results after conversion to Roux-en-Y gastric banding. Obes Surg 2004; 14:381-386.

16. Chevallier JM, Zinzindohoue F, Douard R, Blanche JP, Berta JL, Altman JJ, Cugnenc PH. Complications after laparoscopic adjustable gastric banding for morbid obesity: Experience with 1,000 patients over 7 years. Obes Surg 2004; 14:407-414.

17. Blat S, Guérin S, Chauvin A, Bobilier E, Le Cloirec J, Bourguet $\mathrm{P}$, Malbert $\mathrm{CH}$. Role of vagal innervation on intragastric distribu- 
tion and emptying of liquid and semisolid meals in conscious pigs Neurogastroenterology and motility 2001; 13:73-80.

18. Gao F, Liao D, Zhao J, Drewes AM, Gregersen H. Numerical analysis of pouch filling and emptying after laparoscopic gastric banding surgery. Obes Surg 2008; 18:243-250.

19. Winkler JT. The fundamental flaw in obesity research. Obesity Reviews 2005; 6:199-202.

20. Coskun H, Duran Y, Dilege E, Mihmanli M, Seymen H, Demirkol MO. Effect of gastric emptying and weight reduction of botulinum toxin-A injection into gastric antral layer: An xperimental study in the obese rat model. Obes Sug 2005; 15:1137-1143
21. Cardoso-J. A, Vaz Coelho LG, Savassi-Rocha PR, Vignolo MC, Abrantes MM, de Almeida AM, Dias EE, Junior GV, de Castro MM, Lemos YV. Gastric emptying of solids and semi-solids in morbidity obese and non-obese subjects: An assessment using the ${ }^{13} \mathrm{C}$-octanoic acid and ${ }^{13} \mathrm{C}$-acetic acid breath tests. Obes Surg 2007; 17:236-241.

22. Donohoe KJ, Maurer AM, Ziessman HA, Urbain JLC, Royal HD. Procedure guidline for gastric emptying and motility. J Nucl Med 1999; 40:1236-9. 